\title{
RELIGIÃO, POLÍTICA E EDUCAÇÃO: CONCEPÇÕES DE RACISMO RELIGIOSO DOS PROFESSORES DO ESTADO DO AMAPÁ
}

\author{
Elane CARneiro de AlbuquerquE* \\ MARCOS ViNICIUS DE FREITAS REIS**
}

\begin{abstract}
Resumo: Este artigo apresenta um recorte das análises desenvolvidas a partir do processo investigativo que teve como proposta estudar as relações étnico-raciais na educação escolar com foco nas concepções de racismo elaboradas por professores(as). Parte-se da compreensão de que tais concepções têm sido fator importante no processo de efetivação do Artigo 26A da Lei de Diretrizes e Base da Educação Nacional, Lei n. 9394/96, alterada pela Lei n. 10.639/03 e Lei n. 11.645/08, que instituem os conteúdos de história e cultura afro-brasileira e indígena nos currículos escolares. O estudo foi realizado em uma escola da rede pública estadual situada na periferia de Macapá, capital do estado do Amapá, utilizando-se como dispositivo metodológico uma formação pedagógica continuada, tendo como público-sujeito os(as) professores(as) e técnicos(as). A pesquisa objetivou ainda, identificar as manifestações do racismo no espaço escolar e as suas implicações na identidade da criança negra e não negra; entender como os(as) professores(as) concebem o racismo em suas práticas docentes; e analisar o papel dos(as) professores(as), da escola e das formações pedagógicas na desconstrução do racismo na escola. $O$ estudo aponta para a vigência do racismo no âmbito escolar e, especificamente, do racismo religioso, presente nas ausências, nos silêncios, nas falas e nos não ditos que compõem o currículo escolar, as matrizes curriculares e as práticas docentes do cotidiano da escola. Aponta ainda para a necessidade de investimento e de reformulações nas formações para professores(as), a fim de ultrapassar as resistências dos sujeitos e implementar a legislação e ações afirmativas para uma educação antirracista.
\end{abstract}

Palavras-chaves: Educação. Racismo. Racismo religioso. Professores(as).

\section{Religion, politics and education: religious racism conceptions of the Amapá's teachers}

Abstract: this article presents a review of the analyzes developed from the investigative process, whose purpose was to study ethnic-racial relations in school education through conceptions of racism elaborated by teachers. It is based on the understanding that such conceptions of racism have been an important factor in the process of implementing Article 26-A of the National Education Guidelines and Basis Law, Law no. 9394/96, as amended by Law no. 10,639 / 03 and Law n. 11.645 / 08, which establish the contents of Afro-Brazilian and indigenous history and culture in school curricula. The study was carried out at a state public school located in the outskirts of Macapá, capital of the state of Amapá, using as a methodological device a continuous pedagogical training, having as subject-audience the teachers and technicians ( at). The research also aimed to identify the manifestations of racism in school and its implications on the identity of black and non - black children; understand how teachers conceive racism in their teaching practices; and to analyze the role of teachers, school and pedagogical formations in the deconstruction of racism in school. The study points to the prevalence of racism in schools and, specifically, religious racism, which is present in the absences, silences, speeches and non-sayings that make up the school curriculum, curricular matrices and teaching prac-

\footnotetext{
* Mestre em Educação pela Universidade Federal do Ceará (2008). E-mail: elane.a@hotmail.com

** Doutor em Sociologia pela Ufscar. Coordenador do Grupo do Centro de Estudos Políticos, Religião e Sociedade (Cepres). Professor do curso de Relações Internacionais da Universidade Federal do Amapá (Unifap). E-mail: marcosvinicius5@yahoo.com.br
} 
tices of daily life at school. It also points to the need for investment and reformulations in teacher training in order to overcome the resistance of the subjects and to implement legislation and affirmative actions for an antiracist education.

Keywords: Education. Racism. Religious racism. Teachers.

\section{Introdução}

O contexto amapaense possibilita um fecundo estudo de questões importantes no âmbito das relações étnico-raciais na educação. Destaca-se que quase $80 \%$ de sua população é constituída por negros e pardos (IBGE, 2010) e que, por força da legislação federal, tímida e recentemente a Universidade Federal do Amapá (Unifap) e demais instituições públicas de ensino adotaram políticas afirmativas, como, por exemplo, as políticas de cotas. Por outro lado, no âmbito da educação escolar, as iniciativas governamentais são ainda mais tímidas, especialmente quando se referem à implementação do Artigo 26-A da Lei de Diretrizes e Bases da Educação Nacional (LDB), Lei n. 9.394/96 (Lei n. 10.639/03 e Lei n. 11.645/08)

Por outro lado, desde a aprovação da lei de cotas, evidenciava-se em todo o Brasil o debate em torno da intolerância religiosa e do racismo religioso, tendo em vista a repercussão do aumento dos casos de violência contra as religiões de matrizes africanas na mídia nacional e nas redes sociais, exigindo da universidade e da escola o enfrentamento dessas situações criadas pela vigência do racismo e das desigualdades raciais no Brasil e na educação.

Assim, o texto ora apresentado centra-se no debate em torno do racismo religioso e da intolerância religiosa apontados durante o processo investigativo que teve como proposta compreender como os(as) professores(as) concebem o racismo na escola; identificar as manifestações do racismo no espaço escolar e as implicações dele na identidade da criança negra e não negra; além de analisar o papel dos(as) professores(as), da escola e das formações pedagógicas na desconstrução do racismo na escola. Focalizou-se, então, a seguinte questão norteadora: Quais as concepções de racismo elaboradas por professores(as) do Ensino Fundamental I?

O processo de investigação foi realizado no período de outubro de 2015 a junho de 2016. Para a produção de dados sobre a temática investigativa, optou-se pela realização de uma formação continuada para as relações étnico-raciais na escola junto 
a professores(as) de uma escola estadual da rede pública do Amapá, desenvolvida em dezembro de 2015 em parceria com o Núcleo de Estudos Afro-Brasileiros da Universidade Federal do Amapá (Neab-Unifap) e com o movimento social negro através da Comunidade Tradicional de Matriz Africana Ilê Axé Ibi Olufonnin, tendo como públicosujeito professores(as) e técnicos(as) da educação que atuam nos dois turnos da escola. Por meio da realização de uma formação continuada, procurou-se identificar e analisar as falas, discursos, silêncios e comportamentos de professores(as) a respeito da temática durante a proposta de formação, a fim de encontrar pistas e indícios das concepções de racismo elaboradas por eles.

Assim, o estudo aponta para a emergência de reformular os projetos políticospedagógicos e das matrizes curriculares das escolas e dos cursos superiores de formação de professores(as), assim como de repensar as práticas docentes no sentido de incluir os conteúdos de história e cultura africana e afro-brasileira como meio de enfrentar e combater o racismo na escola, possibilitando aos alunos(as) negros(as) e também aos(as) professores(as) a construção de uma identidade negra positiva.

Considerando que a proposta desta investigação se realiza na relação com os sujeitos e suas interações com a temática étnico-racial na educação em seus espaços de sociabilidade cotidiana, esta pesquisa se identifica com os referenciais teóricometodológicos das abordagens qualitativas em educação. Apresenta-se como um estudo de natureza básica, de cunho exploratório e explicativo sobre um processo de integração, possibilitando a compreensão das relações entre o público-sujeito e suas concepções de vida e profissional, ou seja, a compreensão dos comportamentos na perspectiva dos sujeitos.

Utilizou-se inicialmente de pesquisa exploratória por meio de questionário, com o objetivo de diagnosticar as condições e necessidades do público-sujeito para o planejamento, definição de objetivos e aprofundamento das questões relacionadas ao tema, e procedimentos necessários para a pesquisa-ação, a qual, segundo Thiollent (1985), é um tipo de pesquisa particular participante que supõe intervenção participativa na realidade social, exigindo, portanto, o envolvimento do(a) pesquisador(a) e a ação por parte das pessoas ou grupos envolvidos no problema.

Realizaram-se, ainda, levantamentos em fontes secundárias por meio de pesquisa bibliográfica (referencial teórico) e documental (histórico da escola, projeto polí- 
tico pedagógico, registros de funcionários), além de observações informais no espaço investigativo (comportamentos de professores(as) e do corpo técnico pedagógico e gestor), a fim de identificar, nas práticas pedagógicas desenvolvidas, na organização do espaço escolar, nos ritos e falas cotidianas, indícios de como se estabelecem as relações étnico-raciais na escola.

Para as análises dos dados, utilizou-se a pesquisa explicativa, considerando-se que esta teve como proposta elucidar os motivos e estabelecer quais fatores contribuem ou são determinantes para a ocorrência do racismo no espaço escolar, explicando as possíveis razões e aprofundando o conhecimento sobre essa realidade específica. Além disso, foram realizadas análises dos registros audiovisuais e de fotografias produzidos durante a formação continuada, além de avaliações escritas realizadas pelo grupo-sujeito, dos relatórios e de um segundo questionário aplicado ao grupo pesquisado durante a primeira etapa da formação da pesquisa-ação, ambos produzidos pelo Neab.

\section{Artigo 26-A da LDBN: a Lei n. 10.639/03 e a formação de professores como proposta para a educação antirracista na escola}

Os estudos sobre as relações étnico-raciais na educação apontam para uma história de luta empreendida pelos movimentos negros em busca do reconhecimento e valorização da diversidade das raízes culturais por meio do acesso à educação e pela ampliação dos currículos em todos os níveis do ensino brasileiro, especialmente nas séries iniciais e nos cursos superiores de formação de professores(as): pedagogia e demais licenciaturas.

Em termos de legislação, Dias (2005) aponta que o projeto de Lei n. 4.024/61 já apresentava indícios dessa temática em seu Título I - Dos Fins da Educação: Artigo 1으, Alínea $\mathrm{g}$ - "A condenação a qualquer tratamento desigual por motivo de convicção filosófica, política ou religiosa, bem como a quaisquer preconceitos de classe ou de raça".

A Constituição Federal de 1988, em seu artigo 50, afirma que a educação é um direito de todos e dever do Estado e da família, a fim de promover o pleno desenvolvimento da pessoa; e no artigo 6ㅇ ratifica os princípios de igualdade de condições para o acesso e a permanência na escola. O artigo 210 indica a necessidade de garantir e 
valorizar a diversidade cultural da sociedade, através da fixação de conteúdos mínimos no ensino fundamental que assegurem a formação básica e o respeito aos valores culturais e artísticos, nacionais e regionais (Cavalleiro, 2005).

Mas foi somente a partir da Lei n. $10.639 / 03^{1}$ que a temática étnico-racial tomou visibilidade maior entre professores(as) e pesquisadores(as), adentrando, ainda que timidamente, nas escolas e universidades brasileiras e nos cursos de formação de professores(as), principalmente nos cursos de história e de pedagogia.

A Lei de Diretrizes e Bases da Educação Nacional (LDBEN), Lei $n$. 9.394/1996, em seu artigo 26-A, expressa uma das ações públicas que buscam minimizar as desigualdades raciais e sociais valendo-se da promoção de uma educação antirracista e antidiscriminatória. Trata-se de uma política educacional controversa, pois exige situar-se num movimento contraditório e complexo que comporta diferentes direções (Custódio; Foster; Superti, 2013, p. 169).

A Lei n. 10.639, de 9 de janeiro de 2003, altera a Lei n. 9.394/96 nos seus artigos 26 e 79, tornando obrigatória a inclusão no currículo oficial de ensino de história e cultura afro-brasileira. Foi regulamentada pelo Conselho Nacional da Educação através da Resolução n. 1, de 17 de junho de 2004, das Diretrizes Curriculares Nacionais para a Educação das Relações Étnico-Raciais.

Art. 10 A Lei n. 9.394, de 20 de dezembro de 1996, passa a vigorar acrescida dos seguintes arts. 26-A, 79-A e 79-B:

Art. 26-A. Nos estabelecimentos de ensino fundamental e médio, oficiais e particulares, torna-se obrigatório o ensino sobre História e Cultura Afro-Brasileira.

$\S 1$ O O conteúdo programático a que se refere o caput deste artigo incluirá o estudo da História da África e dos Africanos, a luta dos negros no Brasil, a cultura negra brasileira e o negro na formação da sociedade nacional, resgatando a contribuição do povo negro nas áreas social, econômica e política pertinentes à História do Brasil.

$\S 2$ 으 Os conteúdos referentes à História e Cultura Afro-Brasileira serão ministrados no âmbito de todo o currículo escolar, em especial nas áreas de Educação Artística e de Literatura e História Brasileiras (Lei n. 9.394, de 20 de dezembro de 1996).

Passados mais de 10 anos de sancionada, algumas mudanças ocorreram dentro

\footnotetext{
${ }^{1}$ A Lei n. 10.639/03 foi alterada pela Lei n. 11.645, de 10 de março de 2008, incorporando a história e a cultura dos povos indígenas brasileiros.
} 
do sistema escolar em nosso país referentes ao material didático, pedagógico e tecnológico; no entanto, o racismo continua vitimando pessoas negras dentro da escola, indicando que a Lei n. 10.639/03 ainda não se constitui em uma política educacional mais abrangente e sólida (Videira, 2013).

Para Silva (2007), as dificuldades para a implementação das Diretrizes Curriculares Nacionais para a Educação das Relações Étnico-Raciais e para o Ensino de História e Cultura Afro-Brasileira e Africana, ultrapassam a falta de material didático e de referenciais teóricos, a insuficiência do currículo da formação inicial e a falta de formação continuada, situando-as na própria construção histórica brasileira:

As dificuldades para implantação dessas políticas curriculares, assim como a estabelecida no art. 26 da Lei n. 9.394/1996, por força da Lei n. 10.639/2003, se devem muito mais à história das relações étnicoraciais neste país e aos processos educativos que elas desencadeiam, consolidando preconceitos e estereótipos, do que a procedimentos pedagógicos, ou à tão reclamada falta de textos e materiais didáticos. Estes, hoje já não tão escassos, mas nem sempre facilmente acessíveis. No entanto, não há como desconhecer experiências desenvolvidas por professores negros e não negros, na sua grande maioria contando com apoio do Movimento Negro e que com certeza proporcionaram apoio para a formulação do Parecer CNE/CP n. 3/2004, bem como serviram de exemplo e suporte para que se execute esta determinação legal (Silva, 2007, p. 500).

Nessa mesma perspectiva, Gomes (2011, p. 116) argumenta que, mesmo identificando os limites, esses instrumentos jurídicos apresentam uma inflexão na educação brasileira como parte de políticas de ação afirmativa voltadas para a valorização da identidade, memória e cultura negras. Porém, o desencadeamento desse processo não significa o enraizamento na prática das escolas da educação básica, superior e nos processos de formação inicial e continuada de professores(as), pois estas entram em confronto com as práticas e com o imaginário racial presentes na estrutura e no funcionamento da educação brasileira, entre elas o racismo, a ideologia do branqueamento e a naturalização das desigualdades raciais.

Assim, a formação de professores(as) para as relações étnico-raciais na educação é fundamental para a implementação de uma educação antirracista, considerando o lugar de centralidade dos(as) professores(as) para o desenvolvimento da educação escolar e da construção do currículo com ênfase na construção da identidade não so- 
mente dos(as) alunos(as), como também dos próprios professores(as).

\begin{abstract}
O educador e o educando fazem leitura do mundo, da nação, cidade, bairro, rua, escola e sala de aula e processam suas sínteses. No seu cotidiano, questionam situações de exercício de poder, situações de afetividade, como vivem as diferenças étnico-raciais, como se comportam em situações de conflito, que lazer praticam, onde e como moram, como vivem as relações familiares, que valor dão às amizades, que compreensão têm da escola, de solidariedade, justiça, cooperação.

Na verdade, tudo isso forma um conjunto de relações a partir das quais o educador ou educando lê a si mesmo e ao mundo, num processo relacional. E é nesse conjunto de relações que o racismo se explicita e perpassa o currículo, de forma quase imperceptível para muitos (Rocha, 2005, p. 209).
\end{abstract}

Nesse sentido, Rocha (2005) indica algumas estratégias para a reorientação curricular e formação de educadores(as). Entre elas, destacam-se: 1) A construção de materiais pedagógicos e curriculares contra-hegemônicos tendo como uma das bases o conhecimento acumulado pelo movimento negro; 2) A desfetichização da visão impregnada no currículo de datas comemorativas, que na maioria das vezes reforçam o colonialismo.

Pinto (1999) comenta ainda sobre a necessidade de formação de professores(as) preparados para atuar a partir do novo contexto educacional que incluiria, tendo por base os Parâmetros Curriculares Nacionais (PCN), questões como as diferenças de sexo, cultura, etnia, valores, opiniões ou religiões. Para a autora, os assuntos referentes à diversidade étnico-racial na formação de professores(as) são praticamente ignorados, colaborando para o despreparo do(a) professor(a) para lidar com situações que ocorrem em razão dessa diversidade. E ela indaga: até que ponto essa dificuldade de ver e de se posicionar perante as diferenças étnico-raciais está relacionada com a formação do(a) futuro(a) professor(a)?

O cenário aponta, portanto, a necessidade de um professor capacitado para se posicionar criticamente perante tais reflexões, compreender e desenvolver os conteúdos e alcançar os objetivos propostos nos Parâmetros. Por sua vez, tendo em vista a complexidade das questões sociais, culturais e étnicas destinadas a fundamentar o tema Pluralidade Cultural, os próprios Parâmetros chamam a atenção para a necessidade de a escola e, consequentemente, o professor instrumentalizarem-se para fornecer informações mais precisas a questões 
que vêm sendo respondidas, de modo indevido, pelo senso comum, ou ignoradas por um silencioso constrangimento.

Nesse contexto, torna-se muito oportuno indagar em que medida o curso de magistério está proporcionando aos seus alunos a oportunidade de refletir sobre as diferenças étnico-raciais de modo geral e, de modo particular, no contexto da escola. Essa questão torna-se mais crucial, tendo em vista a concepção abstrata de aluno que os cursos de formação de professores tendem a transmitir aos futuros professores. Não se discutem as condições concretas enfrentadas pelos diferentes grupos de alunos; parte-se do pressuposto de que a nossa sociedade é homogênea (Pinto, 1999, p. 2016).

No entanto, na prática, o que se percebe é que essa nova concepção da educação ainda está em fase embrionária na formação dos(as) futuros(as) profissionais da educação.

Candau e Moreira (2003, p. 166), discutindo sobre a educação escolar na perspectiva da multiculturalidade crítica ${ }^{2}$, apontam que a formação docente, tanto a inicial como a continuada, precisa ser um ponto prioritário, a fim de promover a reflexão de cada educador e educadora sobre a sua própria história cultural e o aprofundamento da temática da formação cultural brasileira, permitindo questionar e desmistificar o "mito da democracia racial" e as leituras hegemônicas da nossa cultura, assim como as relações entre os diferentes grupos sociais e étnicos, analisando as questões curriculares e a dinâmica interna da escola.

O que sabemos sobre história e cultura afro-brasileira? O que sabemos sobre história da África? Como não reproduzir leituras e discussões estereotipadas sobre o negro e sua cultura? Que temas deveremos privilegiar dentro do vasto campo de estudo sobre a cultura afro-brasileira? São questionamentos novos que os docentes e os cursos de formação de professores começarão a fazer (Gomes, 2011, p. 180).

Portanto, a formação do professor precisa reconhecer que os conteúdos curriculares com base eurocêntrica não conseguem abranger o potencial da produção cultural brasileira em seus diversos aspectos. É necessário estimular o diálogo com a riqueza cultural identificada na escola e nos demais espaços educativos da nossa socie-

\footnotetext{
${ }^{2}$ Segundo os autores, "o multiculturalismo crítico (Stoer; Cortesão, 1999) corresponde a uma perspectiva emancipatória que envolve, além do reconhecimento da diversidade e das diferenças culturais, a análise e o desafio das relações de poder sempre implicadas em situações em que culturas distintas coexistem no mesmo espaço" (Candau; Moreira, 2003, p. 161).
} 
dade, em que negros constroem suas identidades e são pouco considerados pelo campo da educação.

Considerando que as políticas públicas de educação são realizadas por agentes públicos nas instituições de ensino, é importante não somente o investimento em formação, mas, principalmente, identificar e entender onde reside a resistência desses sujeitos e, portanto, conhecer a concepção de racismo elaborada por eles como ideologia que permeia suas ações pedagógicas e que é fator da durabilidade da desigualdade entre negros e não negros na educação e na sociedade brasileira.

\section{Sobre as concepções de racismo de professores(as) em formação continuada}

Ao analisar os discursos sobre raça e etnicidade vinculados à ideia de representação regional amazônica, Silva (2008) afirma que, segundo o discurso nativo, a representação simbólica da Amazônia tem como matriz as populações indígenas e ribeirinhas, conhecidas como os caboclos.

No Amapá, estado da região amazônica, os dados oficiais de 2010 do Instituto Brasileiro de Geografia e Estatística (IBGE) demonstram que a população é constituída de $20,3 \%$ branca, $4,5 \%$ preta, $74,4 \%$ parda e $0,8 \%$ indígena. No entanto, como indica Foster (2015), existe no estado, como em toda a região, um forte imaginário coletivo em torno da miscigenação a partir da relação entre índios e brancos. Essa ideia é fortemente representada nas exposições do Museu Sacaca, importante instituição pública de pesquisa, cultura e turismo no Amapá, fortalecendo a percepção racista em torno da população negra no estado.

É interessante como o amazônico, em geral, parece acreditar firmemente que ele descente ou de índios, diretamente, ou da mistura de índios com brancos. A influência do negro raramente é aventada como possibilidade, na formação da população amapaense e paraense. O negro, portanto, parece não constar no imaginário das pessoas, como um brasileiro ou como um amazônico. Ele tem sido, historicamente, uma presença distante, ausente das preocupações sociais e políticas. Entretanto, o racismo é uma realidade nas sociedades amazônicas, muito embora, quase sempre, desvirtuada, desconsiderada como uma questão que merece séria preocupação [...] O negro é um elemento que agora vem sendo considerado por força de luta dos negros nessa região (Foster, 2015, p. 235). 
Outro aspecto importante a destacar para compreender os sujeitos desta pesquisa é a relevância das comunidades quilombolas no estado. Até 2011, foram identificadas 138 comunidades remanescentes de quilombolas e, destas, 31 são certificadas pela Fundação Palmares. Na capital, Macapá, são nove comunidades quilombolas certificadas e mais quatro em processo aberto para a emissão da certidão: Campina Grande, Carmo do Maruanum, Rio Pescada e Ressaca da Pedreira (Silva, 2012). Em 2013, a Fundação Palmares identificou mais duas comunidades: Retiro de Santo Antônio, em Macapá, e Carvão, em Mazagão ${ }^{3}$.

Dessas comunidades quilombolas, a da Lagoa dos Índios fica nos contornos da escola desta pesquisa, a qual atende também crianças do bairro Goiabal e do Distrito do Coração, comunidades com forte presença negra ${ }^{4}$. Dessa forma, percebe-se que a escola se situa em um território permeado dos elementos culturais e identitários negros e "não reconhecer essas informações como relevantes para as ações educacionais no âmbito das políticas públicas é fortalecer o racismo institucional ainda presente nos aparelhos estatais" ${ }^{5}$ (Albuquerque, 2014).

Foster (2015) indica uma relação entre o processo de discriminação racial sofrido por crianças negras com a formação dos professores(as), pois estes, sem certos conhecimentos teóricos e pedagógicos necessários para a prática docente, reproduzem clichês, frases de cunho racista, atitudes e práticas racistas, muitas vezes ornamentados por um discurso de educação para a cidadania.

No que tange às características culturais, quando solicitadas informações sobre

\footnotetext{
${ }^{3}$ Dados disponíveis em: http://www.palmares.gov.br/quilombola/?estado=AP.

${ }^{4}$ Em 2015, a escola atendeu cerca de 378 crianças em 16 turmas, distribuídas em dois turnos (manhã e

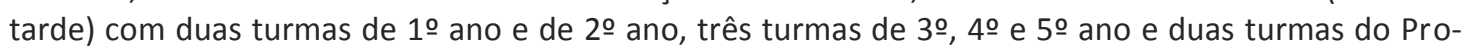
grama de Aceleração de Aprendizagem, oferecendo ainda o Atendimento de Educação Especial (AEE). Em junho deste mesmo ano, a escola recebeu um professor de Ensino Religioso do Contrato Administrativo, porém o professor ali permaneceu somente até o término do 3 o bimestre, em setembro. A escola contava então com 30 professores(as) e duas pedagogas, além de técnicos administrativos, totalizando 59 funcionários

5 Entre os documentos de orientação da ação pedagógica, a escola teve como documento orientador, até 2015, o Projeto Político Pedagógico (PPP) de 2009. No final de 2015 e início de 2016, realizou a avaliação e reelaboração desse documento, feito com a participação de todos(as) os servidores(as). Nesse novo PPP, incorporou a questão da diversidade étnico-racial, tendo em vista as exigências legais. No que se refere ao perfil dos(as) professores(as), somente 18 deles(as) devolveram o questionário da pesquisa exploratória (diagnóstica). Entre eles(as), a maioria é do sexo feminino; 14 têm idade entre 30 e 50 anos e mais de dez anos de atuação profissional, portanto, pessoas com mais maturidade e experiência de vida e profissional. Desses(as) professores(as), 15 fizeram graduação, sendo que, desses(as), dez fizeram o Curso de Pedagogia e somente cinco fizeram curso de pós-graduação (nível de especialização).
} 
religião, seis pessoas não responderam e, das que responderam, a maioria é evangéli$\mathrm{ca} /$ protestante. Somente uma pessoa se declarou ateia.

$\mathrm{Na}$ questão cor, a maioria respondeu ser parda, similarmente à autodeclaração de grande parte dos(as) brasileiros(as). Porém, duas pessoas se declararam pretas. 0 que também chama atenção é que, ao contrário dos estudos apresentados, nenhuma pessoa se identificou como indígena, embora algumas apresentem fortes traços físicos e culturais de referência indígena.

Nesse aspecto, Lima (2006) indica que adentrar em temas complexos como o da formação em relações étnico-raciais na escola implica trabalhar a identidade das próprias professoras a fim de que elas possam compreender como essas concepções de identidade vêm sendo tratadas em suas vidas pessoais e profissionais, em suas histórias de vida, que acabam por determinar suas trajetórias no magistério, historicamente desqualificadas, desmerecidas e de pouco reconhecimento de seus méritos.

Apesar de somente 18 em um universo de 32 docentes terem devolvido os questionários respondidos, as informações sobre o perfil do grupo-sujeito foram importantes, constatando, por exemplo, que a grande maioria não realizou formação acadêmica continuada (especialização, mestrado e doutorado). O grupo é de maioria feminina e em idade acima dos 30 anos, inserindo-se nas características gerais dos docentes do Ensino Fundamental I de todo o País.

No que se refere à formação inicial, dez pessoas informaram que não conheceram, durante essa formação na área da educação, os conteúdos da história e cultura africana e afro-brasileira. Entre as sete pessoas que falaram que estudaram a temática, duas destacaram que o estudo não foi o suficiente.

Por outro lado, a maioria (12) indicou que trabalha às vezes com esses conteúdos na sua prática docente cotidiana de sala de aula. Cinco disseram que não trabaIham tais conteúdos e somente três encontram dificuldade para trabalhar esses conteúdos em sala de aula por não terem conhecimento deles. A maioria (12) também indicou que a dificuldade encontrada estaria na falta de formação pedagógica e continuada, e somente um(a) professor(a) declarou que a dificuldade seria a falta de incentivo do setor pedagógico da antiga escola.

Dessa forma, pode-se compreender que, embora a formação inicial não tenha oferecido o conhecimento suficiente sobre os conteúdos da história e cultura africana 
e afro-brasileira, a maioria afirma trabalhar tais conteúdos em sala de aula, mesmo que seja às vezes. O problema levantado é: Como esses professores(as), que não receberam formação específica ou receberam pouca formação, podem desenvolver tais conteúdos tão complexos sem correr o risco do superficialismo e folclorização sobre as questões das relações étnico-raciais e da história e cultura africana e afro-brasileira?

Sobre a existência da relação entre esses conteúdos de história e cultura africana e afro-brasileira e as religiões de matrizes africanas como a Umbanda e o Candomblé, embora algumas pessoas não identifiquem essa relação, a maioria a identifica, situando-a nas suas origens africanas. Quando questionadas se a relação entre esses conteúdos e as religiões de matrizes africanas, como a Umbanda e o Candomblé, poderia dificultar a efetivação desses conteúdos no currículo escolar, cinco pessoas responderam que sim, principalmente pela falta de conhecimento das pessoas e pelo preconceito em relação às religiões de matrizes africanas, e ainda devido a um currículo com visão unilateral.

Acerca da participação em uma formação continuada sobre esses conteúdos, dez participantes falaram que participariam para obter maior conhecimento e compreensão do conteúdo, para ajudar na instrumentalização dos conteúdos em sala de aula e por ser importante para a formação do(a) professor(a).

Porém, o que chama a atenção é que sete professores(as) falaram que não participariam de formação nessa temática, e, sobre o motivo, um(a) deles(as) informou que não teria interesse no assunto e seis não responderam o motivo, entrando em contradição com as informações colocadas na questão anterior, em que alguns(mas) responderam que a relação entre os conteúdos de história e cultura africana e a religiosidade de matriz africana poderia dificultar o desenvolvimento desses conteúdos em sala de aula, e também, que desenvolvem tais conteúdos em suas aulas.

Nesse sentido, outra questão emerge: Como superar a dificuldade identificada na falta de formação se não se está disposto a essa mesma formação para o conhecimento dos conteúdos necessários? E por que situar nessa falta a não implementação desses conteúdos na sala de aula, se não se identifica essa importância?

É interessante destacar que o(a) professor(a) que informou que não teria interesse no assunto se declarou evangélico(a). Outro(a) professor(a), que também se declarou como evangélico, respondeu somente às informações sobre o perfil, mas não o 
restante do questionário relacionado aos conteúdos de história e cultura africana e afro-brasileira. Portanto, o que poderia levar um(a) professor(a) a desconsiderar as ações pedagógicas para o reconhecimento da diversidade na escola se não o seu próprio racismo e intolerância?

Pode-se conjecturar que o silêncio de quem não respondeu ao motivo de não participar em formação sobre a temática indicaria uma concepção racista sobre a história e a cultura africana e afro-brasileira, assim como um racismo religioso não manifestado claramente e objetivamente nos questionários. Pode-se ainda ponderar a falta de informação ou uma visão distorcida do papel de educador(a) que se deve desempenhar.

Sobre o que gostariam de saber a respeito desses conteúdos através dessa formação, destacaram-se primeiramente as formas de abordagens e fontes de pesquisa, depois, saber onde encontrar os conteúdos para desenvolver as atividades, seguido dos temas cultura, tradição, contribuições históricas, folclore e direitos (cotas), religião e como se estruturam os conteúdos sobre africanidades.

Finalmente, sobre o conhecimento da Lei n. 10.639/03, sete afirmaram conhecer pouco, e a maioria, nove professores(as), afirmaram que não têm conhecimento dela.

A partir dessas informações, foi iniciada a elaboração do conteúdo programático, metodologia e instrumentos didáticos para a realização da formação continuada proposta para esse grupo de professores(as). Esta etapa foi desenvolvida em parceria com a coordenação de ensino do Neab-Unifap e do Babalorixá Marcos, do templo Ilê Axé Ibi Olufonnin.

A partir de então, os esforços foram para agendar junto à escola a realização da formação. Inicialmente foi sugerido o período dos sábados letivos de novembro, a fim de relacionar a ação pedagógica com o mês da consciência negra e melhor sensibilizar o público-sujeito da escola. No entanto, as datas foram sendo adiadas pela coordenação pedagógica, assim como a redução da carga horária proposta inicialmente. Foi então realizada a adaptação ao calendário e às necessidades da escola, conseguindo-se somente dois sábados letivos de dezembro, no período da manhã, horário em que geralmente aconteciam as reuniões e formações pedagógicas. 


\section{Racismo religioso e intolerância religiosa entre os professores}

Durante esse processo de negociação junto ao corpo técnico pedagógico e aos professores(as), percebeu-se a sua resistência através das expressões, da dificuldade de conseguir pauta de reunião para dialogar e decidir as necessidades da formação. Neste período foram realizadas as observações na escola, percebendo-se a ausência da discussão nos seus projetos, nos conteúdos curriculares e ainda nos seus aspectos visuais, sempre carregados de imagens relacionadas à religiosidade cristã e a uma estética eurocêntrica, desconsiderando o princípio de laicidade do Estado e da escola, e caracterizando o proselitismo religioso no espaço escolar.

Nesse sentido, esses(as) professores(as) fazem parte das gerações de brasileiros(as) educados(as) por um processo de escolarização excludente, de seleção de conteúdos de referência eurocêntrica e de concepção metodológica que nega as formas de conhecimento e de se produzir conhecimento da maioria da população negra e indígena, causando inúmeros danos aos povos negros e indígenas, "traduzidos pelos efeitos do racismo e concretizados cotidianamente nas várias versões das desigualdades sociais encontradas na sociedade brasileira" (Pereira, 2006, p. 40).

A formação proposta foi denominada de "I Formação de Professores(as) para as Relações Étnico-Raciais", apresentando como objetivo instrumentalizar os(as) professores(as) e demais profissionais da educação para os conteúdos de história e cultura africana e afro-brasileira, como meio de enfrentamento ao racismo e à intolerância na escola, além da superação do imaginário negativo em torno da cultura e da história dos africanos e dos afro-brasileiros.

Durante a elaboração da proposta de formação, priorizaram-se os aspectos relativos à subjetividade do grupo-sujeito, suas dúvidas, necessidades e inseguranças diante da temática e dos elementos constitutivos da temática, especificamente os relacionados à identidade e a experiências com o racismo na trajetória de vida pessoal e profissional, ou seja, como os(as) professores(as) articulam a temática da formação com sua vida fora e dentro da escola.

No primeiro dia da formação os(as) professores(as) se atrasaram mais do que o costume em outras atividades da escola. Participaram somente 16 professores(as), sendo que dois(duas) não permaneceram efetivamente porque deveriam estar em 
outra reunião com pais de alunos(as) formandos(as). Nesta etapa, foram desenvolvidos por meio de roda de conversa e intervenção poética os temas "Africanidades Cotidianas", e "Relações Étnico-Raciais na Escola: uma Introdução da História e Cultura Africana e Afro-Brasileira". No início da atividade, as pessoas foram incentivadas a falarem sobre as expectativas em relação à formação e suas experiências com a temática do curso; e durante toda essa formação, os(as) professores(as) participaram com seus depoimentos e suas concepções sobre a temática, suas dúvidas, contribuições e relatos pessoais. Também foi solicitado que fizessem suas avaliações, percepções e concepções de forma escrita através das sanfonas. ${ }^{6}$ Toda a proposta pedagógica foi direcionada para proporcionar uma aproximação com a temática racial, e assim, foi reservado um momento que se denominou de Ajeum, nome que, como se explicou aos participantes, é uma palavra do idioma Yorubá para significar comida sagrada, e foram oferecidas comidas comuns da tradição das comunidades afro-brasileiras, como pipoca, frutas e sucos naturais.

Esta etapa foi finalizada com a negociação junto aos(às) professores(as) sobre o segundo momento da formação, apresentando-se a proposta de realização desta segunda etapa no espaço do terreiro, considerando-se alguns princípios da pesquisa antropológica, a necessidade de conhecer e analisar a cultura negra, a percepção de mundo e a organização social de referência africana presente nas comunidades tradicionais de matriz africana. No entanto, esse momento de negociação foi bastante tenso, surgindo diversas justificativas para que a formação fosse realizada somente na escola, como a dificuldade de condução (embora a escola tivesse transporte escolar). Por fim, foi decidido que as pessoas deveriam ir para a escola no dia marcado da formação, onde seriam acomodadas em carros particulares dos(as) participantes(as) para a condução até o terreiro de candomblé.

No intervalo entre as duas etapas da formação, a coordenação pedagógica e a secretária da escola comunicaram que a participação na segunda etapa da formação da pesquisa-ação, que já seria no dia seguinte, não poderia ser obrigatória para os(as) professores(as). Segundo elas, alguns(mas) professores(as) haviam procurado a coor-

\footnotetext{
${ }^{6}$ Sanfona: Passa-se uma sanfona feita em papel para que os/as participantes escrevam suas impressões ou avaliações sobre as atividades realizadas ou a temática de investigação. No dia seguinte, antes de começar as atividades, as sanfonas são lidas coletivamente e discutidas pelo grupo.
} 
denação pedagógica para falar que estavam sobrecarregados(as) com o preenchimento das cadernetas e por isso pediram para ser liberados(as) naquele sábado letivo da formação para que pudessem realizar o preenchimento das cadernetas escolares. Dessa forma, a equipe gestora resolveu que não iria considerar a atividade como uma ação da escola, e que, portanto, os(as) professores(as) que decidissem por não ir na formação não teriam problemas com faltas. O resultado dessa decisão da equipe técnica viria no dia seguinte, do encontro para a formação na comunidade tradicional de matriz africana llê Axé Obi Olufonnin com a presença de somente três professores(as).

Sobre a proposta de realização de formação no espaço sagrado das comunidades tradicionais de matriz africana, é importante destacar que as dimensões religiosas negras são elementos fundamentais quando se pensa no combate ao racismo a partir do reconhecimento e valorização da diversidade cultural, considerando que nos espaços sagrados de matriz africana preservam-se saberes milenares.

Nesse sentido, na segunda etapa da formação pedagógica deu-se prioridade aos princípios civilizatórios africanos, como a ancestralidade, a organização e as relações de parentescos e a história africana e afro-brasileira, a partir do espaço sagrado das comunidades tradicionais de matrizes africanas.

\begin{abstract}
A ancestralidade é considerada, na formação, como fonte capaz de trazer pulsão, energia, movimento e criatividade para o ambiente escolar e ao mesmo tempo valores materiais e simbólicos, princípios éticos e morais da cultura africana necessários para a formação da identidade cultural e fortalecimento da autoestima dos professores e das crianças negras. Também se constitui como parâmetro de diversidade para crianças brancas (Nascimento, 2006, p. 35).
\end{abstract}

A proposta metodológica foi o desenvolvimento de uma pesquisa de campo a fim de possibilitar aos(as) professores(as) conhecer o espaço social e cultural com referência africana, ou seja, possibilitar conhecer e entender como descendentes de africanos se organizam a partir de sua compreensão de mundo.

O terceiro princípio norteador da formação nessa segunda etapa foi a História africana e afro-brasileira, entendendo que nas comunidades de matrizes africanas essa história é preservada e revivida nos elementos materiais, nos rituais, nas relações sociais. 
Assim como na proposta pedagógica anterior, esta segunda etapa aconteceu em forma de roda de conversa, ou seja, de forma dialogada com as pessoas presentes, abordando os seguintes temas: "Comunidades Tradicionais de Matrizes Africanas: Resistência e Preservação"; "Cosmovisão Africana e Afro-Brasileira nas Comunidades Tradicionais de Matriz Africana"; e "Educação e Processos Pedagógicos nas Comunidades Tradicionais de Matriz Africana".

Uma das professoras perguntou como acontece o registro e a preservação dos ensinamentos, fundamentos, entre outros, nas religiões de matrizes africanas, uma vez que, para os cristãos, esse registro estaria principalmente na Bíblia. Com essa indagação, foi possível explicar e debater sobre a importância da oralidade e da experiência cotidiana no processo pedagógico dos terreiros realizado na prática diária e coletiva, da preservação da cultura material e da memória para a história e cultura africana e afro-brasileira. Discutiu-se ainda sobre o racismo e a intolerância religiosa.

Mostrar a pedagogia do terreiro foi importante, considerando-se que esta é uma possibilidade de compreensão da percepção de mundo com referências na coletividade e na circularidade e demais categorias que formam o universo cultural e filosófico afro-brasileiro. ${ }^{7}$

Para facilitar a compreensão sobre a forma de organização social e espacial dos povos de matriz africana, o babalorixá apresentou às pessoas presentes os locais e o significado dos símbolos religiosos de sua casa, destacando sobre a distorção do aspecto teogônico da divindade Exú, ${ }^{8}$ que, por conta do preconceito e da ignorância, é regularmente relacionado à figura do diabo judaico-cristão.

Nesse segundo momento, as pessoas demonstraram muito interesse, anotavam tudo em cadernos e faziam perguntas. Foi um momento de grande participação

\footnotetext{
${ }^{7}$ Circularidade, Oralidade, Axé, Ludicidade, Memória, Ancestralidade, Cooperativismo/Comunitarismo, Musicalidade, Corporeidade e Religiosidade são princípios civilizatórios africanos identificados no cotidiano das comunidades tradicionais de matriz africana, sejam religiosas ou quilombolas. Tais princípios são vivenciados nas formas de fazer e de conhecer desses grupos, que são passadas de geração em geração através, principalmente, da oralidade. A circularidade está presente no sentar em roda com amigos para contar histórias, fazer música, comer junto, brincar com jogos a partir da compreensão de que a vida é cíclica, e a humanidade inteira permanece unida por esse sentimento circular através da memória, do encontro entre o tempo.

${ }^{8}$ Exu, esfera em iorubá, é o Orixá da comunicação e do movimento, da paciência, da ordem e da disciplina. Por ser o mensageiro entre o Orun (o mundo espiritual) e o Aiye (o mundo material), deve ser o primeiro a receber as oferendas. Na concepção judaico-cristã, foi relacionado ao diabo, tendo em vista suas características provocadoras e, principalmente, indecentes e sensuais.
} 
das professores(as). A formação foi encerrada com falas de avaliação e agradecimentos.

A pesquisa desenvolvida demonstrou que a resistência da escola na efetivação dos conteúdos da história e da cultura africana e afro-brasileira situa-se no racismo, embora não seja algo claro para a gestão e os(as) professores(as) o que é o racismo e como ele tem se manifestado nas suas práticas docentes.

Entre as manifestações, percebe-se que a modalidade do racismo religioso é bastante presente, impedindo professores(as), coordenações pedagógicas e gestão de tratar da questão racial na escola, e, portanto, dos conteúdos de história e cultura africana e afro-brasileira, tendo em vista que esses conteúdos apresentam elementos da cosmovisão das religiosidades de matrizes africanas.

As primeiras pistas do racismo na escola emergiram ainda no processo de negociação para a realização da formação proposta: os adiamentos constantes; a redução da carga horária em apenas oito horas em dois sábados letivos e finalizando com menos de quatro horas, devido aos atrasos do primeiro dia de formação; a fala da coordenação pedagógica em reunião, liberando os(as) professores(as) da atividade do segundo dia de formação para o preenchimento de seus diários de classe; entre outros que discutir-se-ão a seguir.

As expressões corporais e faciais do grupo-sujeito também acabaram por apontar pistas importantes, pois demonstraram incômodo durante as atividades, inclusive durante as reuniões nas quais foram informadas sobre a atividade com a distribuição do material da formação (folder e questionários), indicando como o racismo tem operado na escola. Neste atinente, relata Foster:

Embora esta seja uma questão polêmica e que precise ser bastante discutida, com todos os seus desdobramentos, vejo que a resistência das pessoas é bastante reveladora do preconceito racial e do medo de perder privilégios [...].

Vejo essa questão como um lampejo de uma problemática muito séria e que a escola precisa repensar no bojo das relações educação e sociedade, reorientando nossas análises para esses temas tão ausentes, mas, ao mesmo tempo, tão presentes e pulsantes no cotidiano escolar, atentar para as lacunas, para os fatos pouco esclarecidos e para as "naturalizações" (Foster, 2015, p. 75).

A ausência e o atraso no primeiro dia de atividade também foram bem de- 
monstrativos, tendo em vista que, em outras formações e reuniões nas quais se participou, a frequência e a pontualidade nunca foram problemas. Dessa forma, pode-se compreender que a temática da formação proposta por esta investigação para o grupo foi realmente o fator que resultou na grande ausência e nos atrasos.

No primeiro dia, dos quase 36 funcionários da escola, entre professores(as) e técnicos(as) pedagógicos(as), somente 14 pessoas compareceram na atividade, o que dificultou, inclusive, a apresentação da proposta de atividade do segundo momento em uma comunidade tradicional de matriz africana (Ilê Axé Ibi Olufonnin), demonstrando que as questões das relações étnico-raciais na escola não são discutidas, assim como os conteúdos da história e cultura africana não são implementados, muito mais pela resistência e falta de interesse de grande parte dos(as) profissionais que atuam no espaço escolar, sejam professores(as) ou técnicos(as) da educação, do que pela falta de formação oferecida e de material pedagógico disponível, considerando-se que na biblioteca dessa escola específica encontra-se um material relevante para tais atividades.

Os depoimentos iniciais do grupo apontavam principalmente para o racismo no âmbito pessoal, através de experiências vividas junto aos familiares. Uma das professoras disse que esperava que a formação a ajudasse, por exemplo, a entender melhor seu filho, pois ele é negro, tinha vivido racismo e demonstrava um comportamento cada vez mais introspectivo. O mesmo foi dito por outra professora que tem uma filha caçula mais escura que os demais filhos, a qual não aceita essa diferença, dizendo sempre ser branca.

Nesse sentido, uma outra professora falou que estava se questionando se ela era racista e se de alguma forma estaria sendo racista também na escola: "Nunca me vi preconceituosa, porém vejo que contribuo com ele (o preconceito)".

Para outra professora, o momento de formação contribuiu como estímulo inicial, um despertar, um primeiro passo. "Nas entrelinhas, percebi que o racismo na escola não se dá apenas por ação, mas predominantemente por omissão" (Avaliação escrita na sanfona).

Nesse sentido, é importante que as formações para as relações étnico-raciais na escola considerem a profissão de magistério e as identidades dos(as) professores(as) em formação, ou seja, as questões relativas às subjetividades dos(as) partici- 
pantes devem ser trabalhadas e relacionadas aos temas discutidos a fim de que possam perceber sua própria importância no processo e que "reconheçam o quanto é prejudicial a forma como a escola tradicionalmente lida com esse aspecto, desencorajando-as a reproduzir metodologias 'assépticas' com seus alunos” (Lima, 2006, p. 20).

Sobre a vigência da intolerância e do racismo religioso, a pesquisa de Moraes (2013) ajuda a compreender essa modalidade presente na escola e identificada na pesquisa. O autor revela que, no Amapá, os atos de racismo religioso não são esporádicos, e muitos membros de suas comunidades se sentem como vítimas potenciais de perda da sua identidade étnico-religiosa.

\begin{abstract}
Neste quadro de violência religiosa, com forte apelo psicológico (violência psicológica) para colocar tudo o que é negro como demoníaco, bestial, atrasado, visando a baixar sua autoestima, confundir sua identidade, quebrar os seus espíritos (tirar a coragem, o orgulho étnico-religioso, o ânimo para lutar, dominação das consciências), tem-se todo um discurso de racismo religioso, atuante pela intolerância perpetrada pelo mecanismo do proselitismo predatório, que objetiva desqualificar, tirar a legitimidade e o valor histórico-cultural da contribuição destes afro-religiosos para a formação da religiosidade e da identidade do povo brasileiro (Moraes, 2013, p. 143).
\end{abstract}

Nesse sentido, uma professora destacou que "gostaria muito de continuar participando desta iniciativa, mas não me sinto madura/segura quanto ao ambiente do sagrado. Quero continuar aqui (na escola)" (Avaliação escrita na sanfona). Ou seja, a professora não se sentiu em condições de adentrar no terreiro de candomblé, mesmo estando na posição de professora e pesquisadora do conteúdo cultural das comunidades afro-brasileiras presentes no território religioso.

Por outro lado, a formação pedagógica no terreiro permitiu uma outra percepção do universo filosófico das religiosidades de matriz africana, tendo em vista que uma das participantes falou que concebia agora as religiões de matriz africana como culturas que se perpetuam ao longo da história da humanidade, com uma simbologia própria, seus rituais e misticismos, apontando para a carência de estudos na área.

Sei que preciso de mais estudos sobre essas religiões, pois hoje percebi que não conhecia nada ou bem pouco e que nós professores ainda precisamos aprender bastante para repassar aos nossos alunos (Avaliação escrita na sanfona). 
De fato, quando a escola nega as tradições, as formas africanas de viver e conhecer reelaboradas cotidianamente nas comunidades tradicionais de matriz africana no Brasil, ela está sendo racista, pois espera-se que esse espaço exercite a igualdade de direitos.

As avaliações escritas e as falas dos(as) professores(as) revelaram que o processo de formação foi significativo, inclusive a vivência no território de comunidade tradicional de matriz africana, pois reconheceram que a formação acadêmica inicial não foi o suficiente para conhecerem e compreenderem as relações étnico-raciais na escola, os elementos da cultura e da história africana e afro-brasileira e, principalmente, a questão do racismo e da identidade dos alunos e alunas. Pode-se compreender então que:

O Terreiro de Candomblé constitui-se em mais do que um espaço de culto; ele representa uma reconstrução do mundo africano distante, onde é possível reconstruir ancestralidade, história, valores identitários, enfim, fortalecimento do Ser em toda sua plenitude, condição essencial da existência humana (Barbosa, 2006, p. 70).

Analisando as avaliações dos(as) professores(as) que participaram do momento no terreiro de candomblé, pode-se perceber que a vivência foi muito importante para conhecerem com mais propriedade as matrizes africanas; e também para o próprio "enriquecimento humano enquanto descendente e ignorante desta cultura" (Avaliação escrita na sanfona).

A formação desta pesquisa-ação, caracterizada mais por uma sensibilização, tendo em vista seu curto tempo e dificuldades, possibilitou a esses(as) professores(as), segundo suas avaliações, uma melhor percepção das temáticas desenvolvidas, contribuindo para suas práticas pedagógicas, mas também para as percepções de suas próprias identidades.

\section{Algumas considerações}

A pesquisa revelou que na escola o racismo é identificado, sobretudo, nas ausências, nos silêncios, no invisível, no não dito dos sujeitos. As ausências do componente africano e afro-brasileiro também foram percebidas no currículo e nas práticas 
pedagógicas e na organização do espaço escolar.

Na concepção dos(as) professores(as), o racismo na escola é identificado no âmbito da subjetividade das crianças e nas relações estabelecidas entre as crianças negras e não negras, tirando o foco dessa problemática para a vigência de um currículo escolar eurocêntrico e de práticas docentes que negligenciam a história e a cultura africana e afro-brasileira, assim como para o próprio papel do(a) professor(a) como mediador(a) do processo ensino-aprendizagem na escola.

O estudo identificou a resistência do(a) professor(a) e da escola em reformular sua compreensão de educação a partir do reconhecimento da diversidade cultural, assim como das exigências da legislação brasileira para as relações étnico-raciais na educação.

Essas resistências residem na concepção e compreensão da própria identidade dos sujeitos, na construção do imaginário negativo sobre a religiosidade, a história e a cultura africana e afro-brasileira e na falta de conhecimento de como esses elementos se apresentam na história e na sociedade brasileira.

A pesquisa revelou a necessidade de inclusão do conteúdo sobre ensino religioso nos cursos de formação inicial, neste caso específico, implementado pelo Curso de Pedagogia da Universidade Federal do Amapá, tendo em vista que é disciplina que deve ser ministrada pelo(as) professor(as) do Ensino Fundamental I. Dessa forma, é imprescindível que eles(as) tenham o conhecimento do ensino religioso como ciência da religião, prevenindo a prática do proselitismo nessa disciplina, assim como também possibilitar, ao estudante desse nível, o conhecimento das diversas organizações religiosas, incidindo na desconstrução de uma concepção racista e preconceituosa sobre as religiões afro-ameríndias e demais religiões não hegemônicas na escola, função primordial da educação.

Assim, a formação inicial e continuada para as relações étnico-raciais na educação e para a implementação da Lei n. 10.639/03, embora importante, apenas poderá se realizar a partir do desejo dos(as) professores(as).

\section{Referências bibliográficas}

AGUIAR, Márcia Ângela da S. et al. Diretrizes Curriculares do Curso de Pedagogia no Brasil: Disputas de Projetos no Campo da Formação do Profissional da Educação. Edu- 
cação e Sociedade. Campinas, v. 27, n. 96 - Especial, p. 819-842, out. 2006.

ALBUQUERQUE, Elane Carneiro de; MEIJER, Rebeca Alcântara; PEREIRA, Lincoly Jesus Alencar. Produzindo "Confetos" de Museus no Quilombo do Cria-ú - Macapá - Amapá Amazônia: Subsídios para uma Política de Preservação Cultural. Anais do Congresso Brasileiro de Pesquisadores(as) Negros(as) Ações Afirmativas: Cidadania e Relações Étnico-Raciais. V. 1, n. 1. Belém: UFPA, 2014.

AMARAL, Arleandra Cristina Talin do. Com a palavra, as crianças: Algumas reflexões sobre as relações raciais. In: VALENTIM, Silvano dos Santos; PINHO, Vilma Aparecida de; GOMES, Nilma Lino (org.). Relações étnico-raciais, educação e produção do conhecimento: 10 anos de GT 21 da Anped. Belo Horizonte: Nandyala, 2012. p. 203-219.

BARBOSA, Lícia. Gênero e Sexualidade: Concepção e Metodologia no Projeto Escola Plural: A Diversidade está na Sala. In: LIMA, Maria Nazaré Mota de (org.). Escola plural: a diversidade está na sala de aula: formação em história e cultura afro-brasileira e africana. São Paulo: Cortez; Brasília: Unicef; Salvador: Ceafro, 2006. v. 3, p. 52-65.

BARBOSA, Lindinalva. Dimensões Religiosas Negra e Indígena: a Sagrada Resistência. In: LIMA, Maria Nazaré Mota de (Org.). Escola Plural: a diversidade está na sala de aula: formação em história e cultura afro-brasileira e africana. São Paulo: Cortez; Brasília: Unicef; Salvador: Ceafro, 2006. v. 3, p. 27-37.

BIKLEN, Sari Knopp; BOGDAN, Robert C. Investigação qualitativa em educação: Introdução à teoria e aos métodos. Porto: Porto, 1994.

BRASIL. MEC. Lei n. 9.394, de 20 de dezembro de 1996. Estabelece as diretrizes e bases da educação nacional. Disponível em <https://www2.senado.leg.br/bdsf/bitstream/ handle/id/70320/65.pdf $\geq$. Acesso em: 15 jan. 2017.

BRASIL. MEC. Lei $n^{\circ} 10.639$, de 9 de janeiro de 2003. Altera a Lei $n^{\circ} 9.394$, de 20 de dezembro de 1996, que estabelece as diretrizes e bases da educação nacional, para incluir no currículo oficial da Rede de Ensino a obrigatoriedade da temática "História e Cultura Afro-Brasileira", e dá outras providências. Disponível em: <www.planalto.gov.br/ ccivil_03/leis/2003/L10.639.htm>. Acesso em: 15 jan. 2017.

BRASIL. MEC. CNE/CP 003/2004. Diretrizes Curriculares Nacionais para a Educação das Relações Étnico-Raciais e para o Ensino de História e Cultura Afro-brasileira e Africana. Brasília: MEC, out. 2004.

BRASIL. MEC. Parecer CNE/CP n.: 5/2005. Diretrizes Curriculares Nacionais para o Cur- 
so de Pedagogia. Disponível em: <http://portal.mec.gov.br/cne/arquivos/pdf/pcp05_ 05.pdf $\geq$. Acesso em: 27 jan. 2015.

BRASIL MEC. Lei n. 11.645, de 10 de marco de 2008. Disponível em: <http://www.pla nalto.gov.br/ccivil_03/_ato2007-2010/2008/lei/l11645.htm $\geq$. Acesso em: 20 jun. 2017. CANDAU, Vera Maria; MOREIRA, Antônio Flavio Barbosa. Educação escolar e cultura(s): construindo caminhos. Revista Brasileira de Educação, n. 23, p. 156-168, maio/jun./jul./ago. 2003.

CARVANO, Luiz M.; PAIXÃO, Marcelo. Censo e Demografia: A variável cor ou raça nos interior dos sistemas censitários brasileiros. In: SANSONE, Lívio; PINHO, Osmundo Araújo (org.). Raça: novas perspectivas antropológicas. Salvador: Associação Brasileira de Antropologia, EDUFBA, 2008. p. 25-62.

CAVALLEIRO, Eliane. Discriminação Racial e Pluralismo nas Escolas Públicas da Cidade de São Paulo. In: SECRETARIA DE EDUCAÇÃO CONTINUADA, ALFABETIZAÇÃO E DIVERSIDADE. Educação anti-racista: caminhos abertos pela Lei Federal n. 10.639/03. Brasília: Ministério da Educação, Secretaria de Educação Continuada, Alfabetização e Diversidade, 2005. p. 65-104. (Coleção Educação para Todos)

CUNHA, Lídia Nunes. A população negra nos conteúdos ministrados no curso normal e nas escolas públicas primárias de Pernambuco, de 1919 a 1934. In: ROMÃO, Jeruse. História da Educação do Negro e outras histórias. Brasília: Ministério da Educação, Secretaria de Educação Continuada, Alfabetização e Diversidade, 2005. p. 221-238.

CUSTÓDIO, Elivaldo Serrão; FOSTER, Eugênia da Luz Silva; SUPERTI, Eliane. Políticas públicas e diversidade cultural nas escolas no Amapá. Pracs. Macapá, n. 6, p. 165-178, dez. 2013.

DIAS, Lucimar Rosa. Quantos passos já foram dados? A questão de raça nas leis educacionais: da LDB de 1961 à Lei 10.639, de 2003. In: ROMÃO, Jeruse. História da educação do negro e outras histórias. Brasília: Ministério da Educação, Secretaria de Educação Continuada, Alfabetização e Diversidade, 2005. p. 49-62. (Coleção Educação para Todos)

FOSTER, Eugénia da Luz Silva. Garimpando pistas para desmontar racismo e potencializar movimentos instituintes na escola. Curitiba: Appris, 2015.

GOMES, Nilma Lino. Diversidade Étnico-Racial, Inclusão e Equidade na Educação Brasileira: Desafios, Políticas e Práticas. RBPAE, v. 27, n. 1, p. 109-121, jan./abr. 2011. 
GOMES, Nilma Lino. Alguns termos e conceitos presentes no debate sobre relações raciais no Brasil: uma breve discussão. In: SECRETARIA DE EDUCAÇÃO CONTINUADA, ALFABETIZAÇÃO E DIVERSIDADE. Educação anti-racista: caminhos abertos pela Lei Federal n. 10.639/03. Brasília: Ministério da Educação, Secretaria de Educação Continuada, Alfabetização e Diversidade, 2005. p. 39-62. (Coleção Educação para Todos) GOMES, Nilma Lino. Educação, identidade negra e formação de professores/as: um olhar sobre o corpo negro e o cabelo crespo. Educação e Pesquisa, São Paulo, v. 29, n. 1, p. 167-182, jan./jun. 2003.

GOMES, Nilma Lino. Educação e identidade negra. Aletria: alteridades em questão, Belo Horizonte, Poslit/CEL, Faculdade de Letras da UFMG, v. 6, n. 9, p. 38-47, dez. 2002.

GUIMARÃES, Antônio Sérgio Alfredo. Cor e raça: Raça, cor e outros conceitos analíticos. In: SANSONE, Lívio; PINHO, Osmundo Araújo (org.). Raça: novas perspectivas antropológicas. Salvador: Associação Brasileira de Antropologia, EDUFBA, 2008. p. 63-82. HALL, Stuart. A identidade cultural na pós-modernidade. 11. ed. Rio de Janeiro: DP\&A, 2006.

IBGE. Atlas Nacional do Brasil Milton Santos. Rio de Janeiro: IBGE, 2010.

LIMA, Maria Nazaré Mota de. Por que e como formar professores(as) em História e Cultura Afro-Brasileira e Africana. In: LIMA, Maria Nazaré Mota de (org.). Escola plural: a diversidade está na sala de aula: formação em história e cultura afro-brasileira e africana. São Paulo: Cortez; Brasília: Unicef; Salvador: Ceafro, 2006. v. 3, p. 14-26. (Série Fazer Valer os Direitos).

LOPES, Helena Theodoro. Por uma Educação Pluricultural. Encontro Nacional AfroBrasileiro, Rio de Janeiro, 29 jul./1o ago. 1982. Cadernos Cândido Mendes, Estudos Afro-Asiáticos n. 8-9. Rio de Janeiro: Centro de Estudos Afro-Asiáticos (CEAA), 1983. p. $82-85$.

MORAES, Roberto José Nery. O valor ambiental da religião afro-ameríndia: uma análise acerca da intolerância religiosa no Amapá. Dissertação (Mestrado em Direito Ambiental e Políticas Públicas). Universidade Federal do Amapá (Unifap), Macapá, 2013.

MUNANGA, Kabengele. Rediscutindo a mestiçagem no Brasil: identidade nacional versus identidade negra. Belo Horizonte: Autêntica, 2004.

NASCIMENTO, Valdecir Pedreira. Pressupostos básicos da formação de professores no 
Projeto Escola Plural: a diversidade está na sala. In: LIMA, Maria Nazaré Mota de (org.). Escola plural: a diversidade está na sala de aula: formação em história e cultura afrobrasileira e africana. São Paulo: Cortez; Brasília: Unicef; Salvador: Ceafro, 2006. v. 3, p. 27-37. (Série Fazer Valer os Direitos)

PAULA, Cláudia Regina de. Magistério, reinações do feminino e da brancura: a narrativa de um professor negro. In: ROMÃO, Jeruse. História da educação do negro e outras histórias. Brasília: Ministério da Educação, Secretaria de Educação Continuada, Alfabetização e Diversidade, 2005. p. 187-200.

PEREIRA, Isabelle Sanches. Currículo e Construção Teórico-Metodológica: Uma ação para a desconstrução do racismo na escola. In: LIMA, Maria Nazaré Mota de (org.). Escola plural: a diversidade está na sala de aula: formação em história e cultura afrobrasileira e africana. São Paulo: Cortez; Brasília: Unicef; Salvador: Ceafro, 2006. v. 3, p. 38-51. (Série Fazer Valer os Direitos)

PINHO, Vilma Aparecida de. Jovens negros em processo de "ressocialização": trajetória de vida e escolarização. In: VALENTIM, Silvano dos Santos; PINHO, Vilma Aparecida de; GOMES, Nilma Lino (org.). Relações étnico-raciais, educação e produção do conhecimento: 10 anos de GT 21 da Anped. Belo Horizonte: Nandyala, 2012. p. 167-184.

PINTO, Regina Pahim. Diferenças Étnico-Raciais e Formação do Professor. Cadernos de Pesquisa, n. 108, p. 199-231, 1999.

PIRES, Álvaro Roberto. A hora de rodar a baiana! Preservação das matrizes de origem africana na religiosidade brasileira contra a intolerância. Revista África e Africanidades, ano 1, n. 2, ago. 2008.

QUINTANA, Eduardo. Intolerância Religiosa na Escola: o que professoras Filhas de Santo têm a dizer sobre esta forma de violência. Revista Fórum Identidades, Itabaiana, Gepiadde, ano 7, v. 14, jul./dez. 2013.

ROCHA, Lauro Cornélio da. A formação de educadores(as) na perspectiva etno-racial na rede municipal de ensino de São Paulo (2001-2004). In: ROMÃO, Jeruse. História da Educação do Negro e outras histórias. Brasília: Ministério da Educação, Secretaria de Educação Continuada, Alfabetização e Diversidade, 2005. p. 201-218. (Coleção Educação para Todos)

SANTOS, Anselmo José da Gama. Terreiro Mokambo: espaço de aprendizagem e memória do legado Banto no Brasil. Brasília: Fundação Cultural Palmares, 2010. 
SEYFERTH, Giralda. O beneplácito da desigualdade: breve digressão sobre racismo. In: SEYFERTH, Giralda et al. Racismo no Brasil. São Paulo: Peirópolis; Abong, 2002. p. 1743.

SILVA, José Maria da. Raça, Desigualdade e o Poder da Representação na Amazônia. Pracs: Revista de Humanidades do Curso de Ciências Sociais Unifap, Macapá, n. 1, dez. 2008.

SILVA, M. G. da. Territórios quilombolas no estado do Amapá: um diagnóstico. Anais do XXI Encontro Nacional de Geografia Agrária: Territórios em Disputas, os desafios da Geografia Agrária nas contradições do desenvolvimento brasileiro. Uberlândia: UFU, 2012.

SILVA, Nelson Fernando Inocêncio da. Histórico das Políticas Públicas de Promoção da Igualdade Racial: Breve avaliação dos 20 anos. In: ROSSO, Sadi Dal (org.). Políticas para a promoção da igualdade racial no Brasil: o papel da Seppir. Goiânia: Funape; Programa de Direitos Humanos da UFG, 2009.

SILVA, Petronilha Beatriz. Aprender, ensinar e relações étnico-raciais no Brasil. Educação, v. XXX, set./dez. 2007.

SIQUEIRA, Maria de Lourdes. Identidade e racismo: a ancestralidade africana reelaborada no Brasil. In: SEYFERTH, Giralda et al. Racismo no Brasil. São Paulo: Peirópolis; Abong, 2002. p. 73-85

SOUSA, Neusa Santos. Tornar-se negro: as vicissitudes da identidade do negro brasileiro em ascensão social. Rio de Janeiro: Graal, 1983. v. 4. (Coleções Tendências)

STOER, Stephen R.; CORTESÃO, Luiza. Levantando a pedra. Da pedagogia inter/multicultural às políticas educativas numa época de transnacionalização. Porto: Afrontamento, 1999.

THIOLLENT, Michel. Metodologia da Pesquisa-Ação. São Paulo: Cortez, 1985.

VIDEIRA, Piedade Lino. Batuques, folias e ladainhas: a cultura do Quilombo do Cria-ú em Macapá e sua educação. Fortaleza: Edições UFC, 2013.

Artigo recebido em 01 de agosto de 2017 e aprovado em 18 de setembro de 2017. 